\title{
Antonin Artaud: o ator e a física dos afetos
}

\author{
Cassiano Sydow Quilici
}

"Considero-me em minha minúcia. Ponho o dedo no ponto preciso da fissura, do deslizamento inconfesso."

Antonin Artaud (OC, I*, p. 99) ${ }^{1}$

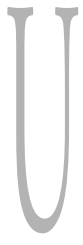

ma das críticas mais comuns aos escritos de Antonin Artaud é a da ausência de proposiçôes claras e metódicas, seja para a encenação, seja para o trabalho do ator. Nesta direção, as observações de Grotowsky (1975, p. 81-9) tornaram-se exemplares. Para o diretor polonês, Artaud seria um "profeta das possibilidades do teatro", pródigo em intuiçôes fulgurantes que não chegam, por uma série de motivos, a se concretizar. Artaud teria nos legado uma profusão de visões e metáforas, mas não um método de trabalho. Tais características teriam gerado, por sua vez, uma série de problemas referentes ao modo de apropriação dos seus textos por artistas posteriores. Grotowsky refere-se especialmente a certas leituras feitas no contexto da contracultura, que aproximavam o "teatro da crueldade" de uma espontaneidade anárquica, mais próxima dos happenings. Con- tra isso, ele pretendeu recuperar o sentido original do termo "crueldade", definido por Artaud, em certa ocasião, como "rigor, aplicação e decisão implacáveis, determinação irreversível, absoluta" (OC, IV, p. 98)

$\mathrm{O}$ diretor inglês Peter Brook, que na década de 1960 também se interessou pelo estudo das idéias de Artaud, num ensaio sobre o Teatro Sagrado (Brook, 1986, p. 51-83) mostrouse igualmente preocupado com algumas reinterpretações do "teatro da crueldade". Suas críticas incidem, principalmente, sobre o ecletismo em voga nas propostas de grupos como o Living Theatre, que misturavam as mais diferentes técnicas (ioga, cabala, exercícios reicheanos, etc.) na busca de uma 'espiritualidade' difusa ${ }^{2}$. Mesmo reconhecendo a vitalidade do grupo norte-americano, Brook critica a somatória indiscriminada de técnicas, apostando, ao invés disso, num processo de subtração e despojamento como modo de se atingir uma comunicação essencial. Como se sabe, tanto Grotowsky como Brook aproximaram-se de tradições artísticas e espirituais milenares, que

* Cassiano Sidow Quilici é professor da Pontifícia Universidade Católica de São Paulo - PUC-SP.

1 As citaçôes das Oeuvres Complètes de Antonin Artaud serão feitas com a sigla OC, seguida do volume e página.

2 Sobre a influência da contracultura e do Living Theatre no teatro brasileiro, ver o irônico ensaio de Rosenfeld, "Living Theatre e o Grupo Lobo" (1993, p. 219-26). 
trabalham com princípios constantes, para construírem suas propostas teatrais.

As consideraçôes desses artistas sobre as limitaçôes e distorçōes das propostas de Artaud servem-nos para estabelecer alguns critérios iniciais, bastante importantes. Em primeiro lugar, contestam a criação de um culto ingênuo e romântico, em torno da figura do poeta "maldito", além da assimilação pura e simples do teatro de Artaud pela ideologia da contracultura. Sublinham as relações entre rigor e espontaneidade como uma das principais contribuições do "teatro da crueldade". Estabelecem também uma distinção fundamental entre a discussão dos "princípios" e da atitude artaudiana frente à arte, e dos "métodos de trabalho" que podem ser daí derivados. Desafiam-nos assim a compreender e a desdobrar as intuições visionárias do poeta, transformando-as em procedimentos concretos. Por fim, levam adiante certas questôes propostas por Artaud, como o problema das relaçōes multiculturais e os contatos entre o Ocidente e o Oriente, tema que ganha uma relevância cada vez maior numa cultura globalizada.

Parece-me, entretanto, que mesmo tais avaliações concentram-se fundamentalmente nos textos que discutem especificamente as questóes teatrais, notadamente os ensaios que compóem $O$ Teatro e seu Duplo. Acredito, no entanto, que no amplo espectro de questôes abertas pela obra artaudiana, encontraremos as marcas de um trabalho sobre o corpo e os estados mentais, que podem ser de grande relevância para o ator. Esta opinião encontra apoio nas observações de Evelyne Grossman ${ }^{3}$ sobre o significado que as palavras "ator" e "teatro" adquirem nos textos de Artaud. Elas não se referem apenas ao exercício de uma profissão, mas passam a designar um projeto de reconstrução do homem e da cultura a partir do corpo, que marcará toda sua trajetória.

Desde a década de 1920, Artaud debruça-se intensamente sobre os próprios processos psico-físicos, impelido pela urgência de lidar com seu sofrimento e pela necessidade de forjar os meios de "refazer-se". Negando o caráter "literário" de seus textos, cria uma poética singular, que pretende expressar "o grito da própria carne" e a reivindicação de um novo corpo. Esta "palavra-grito" tenderá a transbordar o campo literário, tornando-se "poesia no espaço", e tendo no teatro um campo privilegiado de desenvolvimento. Mesmo depois da encenação de $O s$ Cenci, em 1935, última tentativa de realizar suas idéias nos palcos tradicionais, Artaud continuaria utilizando os termos "ator" e "teatro" para referir-se à revolução cultural que pretendia ajudar a desencadear. Talvez só possamos compreender a verdadeira dimensão das suas contribuições para a arte do ator se colocarmos a discussão nesta ampla perspectiva, articulando o teatro com o problema mais geral do agir e da capacidade humana de reconstruir-se corporal e espiritualmente.

\section{Um atletismo afetivo}

O texto mais freqüentemente citado, quando se trata de discutir a visão artaudiana sobre o trabalho do ator, é o ensaio Um atletismo afetivo (OC, V, p. 125-32). Nele encontramos um esforço de definição dos parâmetros que deveriam reger um processo básico de preparação. As indicaçôes, porém, não são suficientemente precisas para se constituírem como um programa ou método de trabalho. Mesmo assim, podemos identificar alguns "princípios" inspiradores. Em primeiro lugar, o campo do ator é definido como o campo dos "afetos". Não devemos entender esta palavra no seu sentido corriqueiro, ligado à expressão das emoções cotidianas, já que Artaud recusa-se a tratar das "paixões medianas". O "teatro da crueldade" não pretende trabalhar com as emoções decorrentes unicamente das relações que os homens estabelecem entre si, num contexto social e psicológico.

3 Refiro-me ao artigo "L'homme acteur", publicado na revista Europe (Grossman, 2002). 
A exemplo das tragédias antigas e dos mitos, trata-se de mobilizar uma certa qualidade de experiência, a "angústia que está na base de toda verdadeira poesia", que brota de confrontações metafísicas, e que para Artaud foram suprimidas do teatro ocidental moderno.

Por outro lado, "afeto" é uma palavra que nos esclarece sobre a eficácia pretendida pelo teatro artaudiano. Ela designa uma espécie de poder de contágio, de capacidade que o teatro teria de "afetar", inclusive organicamente, os que dele participam. Lembremos da famosa analogia entre o teatro e a peste: mais do que comunicar algo, o teatro pode mobilizar e desencadear forças, trazendo à tona e redirecionando o que foi recalcado pela ordem cultural. $O$ poder de afetar também não diz respeito ao efeito de empatia, criticado por Brecht. Os sentimentos que o "teatro da crueldade" deve despertar estão ligados a uma experiência de "estranhamento", de choque sobre as percepções automatizadas. Porém, eles não irão necessariamente conduzir a um processo reflexivo, como quer Brecht. O que mais importa, no caso de Artaud, é a desestabilização das referências cristalizadas e a abertura para uma experiência "vital", ainda não codificada em conceitos.

O desencadeamento dessas dinâmicas afetivas dependeria, por sua vez, de um trabalho físico e plástico com as emoções. Sabemos que, no começo do século XX, a pesquisa das relações entre as emoções e as ações físicas não era exatamente uma novidade. Meyerhold, por exemplo, já trabalhava intensamente nessa direção, influenciando posteriormente Stanislavski. Mas o modo de Artaud tratar a questão possui certas singularidades. Ele recorreria mais uma vez à idéia de "duplo", postulando a existência de um "organismo afetivo" acoplado ao organismo físico. O "organismo afetivo" seria o duplo do corpo físico, uma "efígie espectral" que o ator saberá moldar, o que não deve ser entendido apenas como uma metáfora. $\mathrm{O}$ ponto de contato entre o afeto e o corpo será, precisamente, a respiração. É a respiração que o ator deve saber esculpir, se pretende manejar as forças afetivas. Assim, tem de desenvolver uma percepção aguçada dos fluxos respiratórios, como modo de reconhecer no próprio corpo as sutis variações dos estados afetivos: "a respiração acompanha o sentimento e pode-se penetrar no sentimento através da respiração" (OC, V, p. 129).

Artaud defende também uma curiosa inversão das relações que costumamos estabelecer entre respiração e movimento, e exemplifica sua idéia comparando o ator ao atleta: "enquanto no ator, o corpo é apoiado na respiração, no lutador, no atleta físico, é a respiração que se apoia no corpo". Se o atleta muitas vezes exerce um controle sobre o ritmo respiratório, o seu objetivo principal quase sempre é a performance física visível. No ator o foco deve ser outro. A atenção voltada à respiração remete à intensa concentração nos ritmos do corpo. O afeto é apreendido corporalmente na medida em que o ator desenvolve a percepção das pequenas mutações das sensações expressas, por exemplo, na respiração. Deste modo, a respiração é a base sobre a qual o ator deve construir sua movimentação. Ela precede, por assim dizer, a exteriorização da ação. Pesquisar a respiração significa investigar o nascimento dos impulsos e as transformações sutis dos estados interiores.

Artaud tinha consciência da existência de um conhecimento bastante sofisticado sobre os processos respiratórios e suas conexões com estados afetivos e mentais, desenvolvido no Oriente. ${ }^{4}$ Suas observações sobre a relação entre a exteriorização dos movimentos e a respiração

4 Sobre os estudos de Artaud sobre as culturas orientais pode-se consultar seu ensaio Notes sur le culture orientales, grecques e indiennes (OC, VIII.). A este respeito ver também Borie (1989). Uma exposição panorâmica das técnicas de respiração encontradas nas tradições orientais pode ser encontrada em Eliade (1983). 
fazem-nos também lembrar dos princípios utilizados no teatro clássico japonês, em especial no Nô. A famosa fórmula de Zeami, "expressar o espírito em dez décimos; mover o corpo em sete décimos", afirma justamente a proeminência do movimento interno sobre o externo, lembrando-se que "espírito", no Oriente, não é apenas uma abstração, podendo ser trabalhado através da respiração. Nas palavras de Artaud, a respiração deve ser o "ponto de apoio" do movimento.

Além disso, em Um atletismo afetivo, encontramos também esboçadas algumas relações mais específicas entre a qualidade da respiração e da ação cênica. Assim, se a ação for contida, a respiração deverá ser "ampla" e "sobrecarregada de reflexos”. À ação arrebatadora e expansiva deve corresponder uma respiração em "lâminas curtas”. Em suma, propõe-se uma espécie de inversão ou contraposição das dinâmicas interna e externa. Yoshi Oida, ator do grupo de Peter Brook com experiência no teatro Nô, faz observações na mesma direção:

"Por exemplo, digamos que a ação no palco seja muito violenta ou apaixonada. Se internamente o estado for o mesmo, a ação poderá ser tensa demais. Neste caso mantemos a parte interna bem tranqüila. Se, ao contrário, estivermos interpretando um sujeito calmo ou entediante e nosso interior estiver no mesmo estado, corremos um alto risco de que a interpretação seja insípida. Nesse caso, o interno tem de trabalhar fortemente com intensa concentração e energia." (Oida, 2001, p. 71)

Artaud ainda sugere-nos um sistema de divisão dos tipos de respiração, inspirado na Cabala, que considera diversos modos de combinação da respiração "masculina", "feminina" e "neutra". Mas estes tipos são caracterizados vagamente. $\mathrm{O}$ masculino corresponderia à disposição ativa do querer, expressa na respiração vigorosa. $\mathrm{O}$ feminino é "o tempo de pensar em não querer", uma respiração ligada aos estados de abandono, angústia e súplica. O neutro é genericamente associado a "estados de suspensão". Haveria ainda um outro estado, "acima das respiraçōes", em que o "manifesto combina-se ao não-manifesto". Neste caso, Artaud provavelmente refere-se a uma experiência, conhecida na ioga e nas tradições meditativas do oriente, em que a respiração é tão sutil que se torna quase imperceptível, levando a estados profundos de concentração.

Se tais indicações são evidentemente insuficientes para constituírem um método, têm o mérito de apontar para um campo de investigação bastante fértil, talvez ainda não suficientemente explorado no Ocidente. Refiro-me especialmente aos exercícios de percepção aguçada dos fluxos do corpo, à apreensão das oscilações microscópicas das sensações, dos pequenos impulsos, dos movimentos "moleculares", que têm na respiração um campo privilegiado de expressão. Ao exortar o ator a dedicar-se à ciência da respiração, Artaud não pretende apenas sugerir uma técnica. Trata-se de um caminho de reapropriação de si, em que o corpo não se encontra mais "preso magneticamente às suas mais elementares e mais simples reações nervosas e orgânicas" (apud Virmaux, 1978, p. 323). Tornar-se "ator" significa, portanto, ser capaz de "agir", ou seja, liberar-se das reatividades e dos automatismos profundamente enraizados no organismo, realizando-se assim uma verdadeira revolução fisiológica.

\section{Microfísica do sofrimento}

Uma dimensão ampliada do que é o "ator artaudiano" pode ser apreendida pelo exame de diferentes momentos da sua obra. Na correspondência com Jacques Rivière, e em outros textos importantes da década de 1920, como Pesa-Nervos, Umbigo dos Limbos e A Arte e a Morte, encontraremos a expressão do próprio sofrimento físico e mental aliada a uma espantosa capacidade de sondagem dos movimentos mais sutis e fugidios da experiência interior. Sobre esse período, a ensaísta Susan Sontag afirma que "não há em toda a história da literatura 
em primeira pessoa, um registro tão incansável e minucioso da microestrutura do sofrimento mental" (Sontag, 1985, p. 20). Mesmo o editor da famosa publicação Nouvelle Revue Française, Jacques Rivière, que na época recusou-se a publicar os poemas de Artaud, acabou por reconhecer uma estranha lucidez nas cartas do poeta: "Uma coisa me choca: o contrate entre a extraordinária precisão de seu diagnóstico sobre você mesmo e o vago, ou no mínimo, informe das realizaçôes que você intenta." (OC, $\mathrm{I}^{*}$, p. 34).

Ressaltando-se algumas características básicas dessa produção, revela-se imediatamente sua vizinhança com os problemas suscitados pela arte do ator. Trata-se de uma escrita que, em primeiro lugar, renega veementemente o rótulo de "literatura". O anseio em reaproximar a palavra da experiência psico-física resulta numa escritura encarnada, que pretende ser o "grito mesmo da vida". Experiência que, longe de ser indiferente, é marcada pelo sofrimento, imprimindo um sentido de urgência para o ato de expressão:

"Eu sofro de uma pavorosa enfermidade do espírito. Meu pensamento me abandona em todos os degraus, desde o fato simples do pensamento até o fato exterior de sua materialização em palavras. Palavras, formas de frase, direçōes interiores do pensamento, reaçôes simples do espírito, estou em constante busca do meu ser intelectual. Assim, pois, quando posso agarrar uma forma, por imperfeita que seja, fixo-a, temeroso de perder todo o meu pensamento." (OC, I*, p. 24)

"A percepção do pensamento em estado de erosão impede o estabelecimento de qualquer fundamento seguro para a subjetividade. Mesmo a tentativa de formalização desses fluxos, através da escrita, não fazem desaparecer as marcas da instabilidade do processo. Por isso mesmo, a escrita artaudiana é sempre fraturada e oscilante, não possuindo o acabamento que muitas vezes é exigido do produto literário. Ao mesmo tempo, o mergulho nesta espécie de 'limbo', em que sensações e pensamentos existem em estado larvar sem chegar a adquirir formas claras, tende progressivamente a dissolver a própria noção de um 'sujeito', portador da experiência. A descrição dos estados psico-físicos é feita, muitas vezes, de modo impessoal: 'uma sensação de queimação ácida nos membros, músculos retorcidos e como em carne viva, o sentimento de estar num frasco frágil, um temor, uma retração ante o movimento e o ruído'.” (OC, $I^{*}$, p. 58).

A sondagem cada vez mais profunda dos fenômenos sensoriais parece desembocar na dissolução das representaçôes do corpo como suporte de um "eu” estável e unitário. O que se pretende é aproximar-se da "vida", apreendida como um fluxo que se furta aos enquadramentos conceituais. A identificação entre "vida" e "crueldade", que aparecerá posteriormente em várias formulações de $O$ Teatro e seu duplo, de certa forma já está implícita aqui. As representações tranqüilizadoras de um corpo aparentemente estável, com limites bem definidos, são rechaçadas, dando lugar à apreensão de uma realidade incerta e movediça, da existência como turbilhão, devoração, entrechoque de forças. $\mathrm{O}$ corpo estratificado, codificado e formatado como "organismo", disciplinado pelas normas sociais, é experimentado agora como um "cadinho de fogo e de carne", em que o sofrimento é confrontado sem subterfúgios; ao mesmo tempo, são mobilizadas as forças e as possibilidades de recriação de si mesmo.

Tal operação necessariamente mobiliza angústias arcaicas, já que envolve processos básicos de constituição da "identidade" e das "representações corporais". Ela significaria simplesmente a dissolução e o mergulho num caos, se não exigisse simultaneamente uma espécie de lucidez, mobilizando uma percepção que opera em alta velocidade, uma "mente rápida como pólvora", o "olho intelectual em meio ao delírio", tema que será tratado em diversos textos. Tal forma de inteligência não se confunde com o exercício racional que apreende o real na sua 
regularidade para estabilizá-lo em conceito. Ela atua, o tanto quanto possível, na proximidade das fulgurações e imprevisibilidades da experiência, como um "pesa nervos", que registra sem julgar ou racionalizar:

"No campo do imponderável afetivo, a imagem transportada por meus nervos toma a forma de uma intelectualidade mais alta, a qual me nego a arrancar-lhe o caráter de intelectualidade. E é deste modo que assisto a formação de um conceito que leva a fulguração mesma das coisas, que me chega como um ruído de criação.” (OC, $\mathrm{I}^{* *}$, p. 52)

A expressão, portanto, brotará desse mergulho, não isento de angústia, numa "realidade murmurante", apreendida num ato de coragem e de lucidez exacerbada. Trata-se da mesma atitude que será depois exigida do ator do "teatro da crueldade" visto como um "mártir que emite sinais em meio às chamas". O sentido sacrificial do ato expressivo advém justamente da dissolução da idéia de "sujeito" que tal processo proporciona. $\mathrm{O}$ ator-poeta artaudiano desfaz-se do núcleo da sua subjetividade, centrada na idéia de um "eu" ou de uma "consciência racional" divinizada, destacada do corpo, que comanda e julga. Ao mesmo tempo, não se trata de ceder, pura e simplesmente, ao fascínio do irracional, da loucura ou da destruição. Se o sentido de "eu" é progressivamente afrouxado, se as capacidades de conceituar e julgar são momentaneamente suspensas, recupera-se com grande intensidade a capacidade de estar atento à experiência, penetrando-se em suas minúcias, expondo-se a sua energia e vitalidade. A alquimia só será completa com a presença dessa faculdade "intelectual" de sondagem, desse "olhar vidente" que "percorre vertiginosamente todas as fibras". Portanto, é incorreto identificarmos as proposições de Artaud com um irracionalismo vago e confuso.

Se Artaud não chega a explicitar os modos de desenvolvimento dessa "faculdade intelectual”, mesmo assim pode-se dizer que ela está na base do processo de construção rigorosa dos signos no "teatro da crueldade". O ator, para se transformar num "hieróglifo vivo", deverá possuir os recursos necessários para transitar entre o campo do informe e o território dos signos. Os signos aptos a transmitir esta experiência são aqueles que revestem de imagens e enigmas uma realidade que se furta sempre à clareza e a definição. Se no teatro essa linguagem não chegou a se realizar plenamente, Artaud deixou-nos ao menos os rastros de uma experiência vivida, palavra encarnada que nos contagia até hoje, toda vez que dela nos aproximamos.

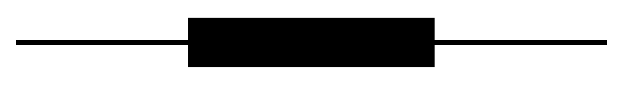

\section{Referências bibliográficas}

ARTAUD, Antonin. Oeuvres Complètes. Paris: Gallimard, 1976-84, tomos I*, I**, II e IV.

BORIE, Monique. Antonin Artaud: Le Théatre et le Retour aux Sources. Paris: Gallimard, 1989.

BROOK, Peter. El Espacio Vacio. Barcelona: Nexos, 1986.

ELIADE, Mircea. Le Yoga: Immortalité et Liberté. Paris: Payots, 1972. 
GROSSMAN, Evelyne. L'homme acteur. Europe (revue littéraire), Paris, n. 873-874, p. 3-13, jan./ fév. 2002.

GROTOWSKY, Jerzy. Para um Teatro Pobre. Lisboa: Forja, 1975.

OIDA, Yoshi. O Ator Invisivel. São Paulo: Beca, 2001.

ROSENFELD, Anatol. Prismas do Teatro. São Paulo: Perspectiva, 1993.

SONTAG, Susan. Sob o Signo de Saturno. São Paulo: LPM, 1986.

VIRMAUX, Alan. Artaud e o Teatro. São Paulo, Perspectiva, 1978. 